\title{
FRESH AUTOGENEIC, FROZEN ALLOGENEIC, AND DECALCIFIED ALLOGENEIC BONE GRAFTS IN DOGS
}

\author{
NIKOLAUS SCHWARZ, GÜNTHER SCHLAG, MARTIN THURNHER, JOSEF ESCHBERGER, \\ HANS P. DINGES, HEINZ REDL
}

From the Ludwig Boltzmann Institute, Vienna

\begin{abstract}
In fully-grown mongrel dogs, diaphyseal ulnar defects $25 \mathrm{~mm}$ long were stabilised by screws and plates, and were temporarily filled with silicone rubber blocks. After eight weeks the block was replaced either by fresh autogeneic cancellous bone, allogeneic deep-frozen cancellous bone, allogeneic decalcified bone matrix, or bone matrix gelatin.

After 24 weeks the implants were evaluated by radiography, histology, and measurements of new bone volume, using computer-assisted density registration on microradiographs.

Only the autogeneic bone grafts led to healing in all instances. Bone regeneration in the other groups was not significantly better than in the sham group in which no graft was employed. Decalcified bone matrix proved ineffective.
\end{abstract}

The osteogenic capacity of decalcified bone matrix may have been exaggerated by experimental data which came mainly from studies in rodents. In these animals, bone matrix can rapidly induce bone formation in nonossifying tissues (Urist 1965) but in other mammals this does not happen. In sheep, allogeneic bone matrix produced only non-specific granulation tissue. Sato and Urist (1985), Thielemann (1985, personal communication) and Lindholm et al (1988), all reported the failure of bone morphogenetic protein (BMP) to induce bone in the muscles of sheep or dogs. Hosny and Sharawy (1985), who implanted pulverised matrix, reported bone induction in monkeys but Aspenberg, Lohmander and Thorngren (1988) were unable to confirm this finding and also reported an experiment which failed to demonstrate osteo-induction by implantation of matrix in the human.

N. Schwarz, MD, Associate Professor, Orthopaedic Surgeon G. Schlag, MD, Professor of Anaesthesiology

M. Thurnher, VMD

H. Redl, PhD, Associate Professor

Ludwig Boltzmann Institute for Experimental and Clinical Traumatology, Donaueschingenstrasse 13, A 1200 Vienna, Austria.

J. Eschberger, MD, Orthopaedic Surgeon

Institute of Osteology, Kundratstrasse 37, A-1120, Vienna, Austria.

H. P. Dinges, MD, Associate Professor

Institute of Pathology, University of Graz, Auenbruggerplatz, A-8036

Graz, Austria.

Correspondence should be sent to Dr N. Schwarz.

(C) 1991 British Editorial Society of Bone and Joint Surgery

0301-620X/91/5173\$2.00

J Bone Joint Surg [Br] 1991; 73-B:787-90.
Most experiments with orthotopically implanted bone matrix have also been performed in rodents. Exceptions include those of Nilsson et al (1986), who used an unstable ulnar defect in dogs to show the osteogenic effect of bovine BMP. The BMP-filled defects healed as promptly as those filled with autogeneic cortical bone chips. However, Johnson et al (1989) found that small ulnar defects in dogs did not heal when filled with bovine BMP, despite plate fixation and preservation of the periosteum over the defect.

Our experiments were undertaken because to date no direct comparison has been made between allogeneic decalcified bone matrix and autogeneic cancellous bone in diaphyseal bone defects of non-rodent mammals.

\section{MATERIALS AND METHODS}

Experimental design. We used 24 fully-grown mongrel dogs (body-weight 20 to $30 \mathrm{~kg}$ ). An ulnar defect was created in the left forelimb and stabilised with a bone plate. It was filled with a Silastic block (Dow Corning Medical SA, Valbonne, France) to prevent interposition of soft tissue and to block regeneration from the bone ends. The animals were mobilised immediately after operation, without external splintage. Eight weeks after the first operation the Silastic block and the newly formed membrane of connective tissue around it were removed. Bone replacement material was implanted into the defect without further preparation of the bone ends. 
The animals were divided into five groups according to the material with which the defects were filled.

i) Sham group: no material was implanted after removal of the Silastic block.

ii) Autogenous cancellous bone: fresh cancellous bone was taken from the animal's greater trochanter on the same side as the ulnar defect.

iii) Bank bone: allogeneic cancellous bone blocks ( $<5 \mathrm{~mm}$ long), were taken from the vertebral bodies of fully-grown mongrel dogs. These had been immersed in liquid nitrogen for three weeks and thawed at room temperature in a Betadine bath (Mundipharma, Limburg/Lahn, Germany).

iv) Demineralised bone matrix (DBM): allogeneic cortical bone was taken from the mid-shaft of the femur and tibia in mongrel dogs. It was mechanically cleaned from blood, periosteum and bone marrow, washed in sterile Ringer's solution, deep-frozen, and finally fragmented with a hammer and a mill. The bone was then freed from fat (chloroform/methanol for one hour at $25^{\circ} \mathrm{C}$ ), decalcified $\left(2 \% \mathrm{HCl}\right.$ for 24 hours, at $\left.4^{\circ} \mathrm{C}\right)$ and lyophilised. Before implantation from the matrix, particles were sterilised ( $25 \mathrm{KGy} \mathrm{Co}^{60}$ ), sieved (diameter 1 to $4 \mathrm{~mm}$ ) and soaked in Ringer's solution at room temperature for ten minutes. v) Bone matrix gelatin (BMG): the decalcified fragmented matrix was further extracted $\left(\mathrm{CaCl}_{2}, 2 \mathrm{~mol}\right.$ for 24 hours, at $4^{\circ} \mathrm{C}$; ethylenediaminetetra acetic acid (EDTA) $0.5 \mathrm{~mol}$

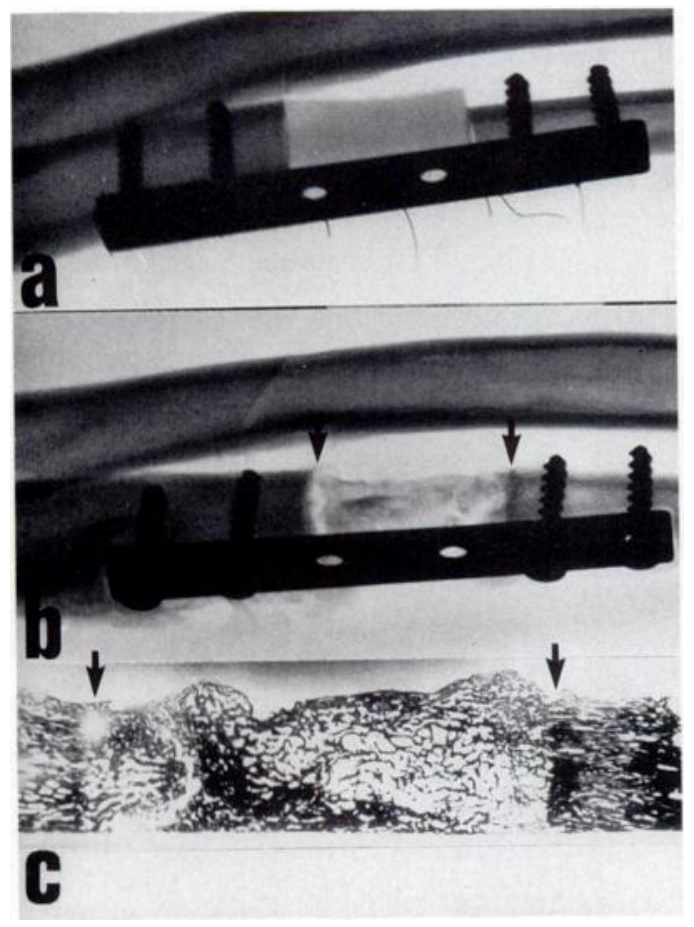

Fig. 1a

Fig. 1b

Fig. 1c

a - A $25 \mathrm{~mm}$ long defect of the shaft of the ulna in a mongrel dog immediately after resection, plate fixation and interposition of a Silastic block; b - 14 weeks later, six weeks after removal of the block and autogeneic bone grafting; c-Microradiograph 24 weeks after grafting.

The arrows mark the extent of the original defect. for 24 hours at $4^{\circ} \mathrm{C} ; \mathrm{LiCl}, 8 \mathrm{~mol}$ for 24 hours, at $4^{\circ} \mathrm{C}$ ) and washed in distilled water for 24 hours at $55^{\circ} \mathrm{C}$. The material was lyophilised, sieved and soaked in Ringer's solution immediately before implantation but was not sterilised. DBM and BMG were stored in airtight containers for three to eight months.

The animals were radiographed every six weeks. They were killed and the specimens obtained 32 weeks after the first intervention, 24 weeks after filling the defect.

Surgical procedure. To create the ulnar defect, the animals were operated on under general anaesthesia with endotracheal halothane. The skin was cleaned with Betadine solution and a $12 \mathrm{~cm}$ long incision was made over the ulna. A 6-hole ASIF plate was fixed to the bone with four $3.5 \mathrm{~mm}$ screws. The plate was then removed and a $25 \mathrm{~mm}$-long segment of diaphyseal bone and periosteum was resected with an oscillating saw under continuous cooling. The plate was then reapplied, simultaneously restoring the original length and immobilising the bone ends. A precut block of Silastic was placed in the defect and fixed with a catgut suture (Fig. 1). The diameter of the resected segment of ulna averaged $8.9 \mathrm{~mm}(\mathrm{n}=9)$. The ratio of its length to its diameter was therefore 2.8 to 1 .

Histological methods and microradiography. The retrieved ulnar specimens were radiographed and then fixed in $10 \%$ formalin for three weeks. After removal of the screws and plate a further radiograph was taken. The specimens were embedded in methylmethacrylate and cut in a plane parallel with the long axis of the ulna. Thin sections were stained by the methods of Giemsa and Masson/Goldner.

Table I. Scoring system for evaluation of plain radiographs and microradiographs (maximum score $=20$ )

\begin{tabular}{|c|c|}
\hline & Points \\
\hline \multicolumn{2}{|l|}{$\begin{array}{l}\text { Plain radiographs } \\
\text { Remaining bone defect }\end{array}$} \\
\hline$>10 \mathrm{~mm}$ & 0 \\
\hline 5 to $10 \mathrm{~mm}$ & 2 \\
\hline$<5 \mathrm{~mm}$ & 4 \\
\hline None & 6 \\
\hline \multicolumn{2}{|l|}{ New bone formation } \\
\hline Resorption or none & 0 \\
\hline Moderate & 1 \\
\hline Marked & 2 \\
\hline \multicolumn{2}{|l|}{ Remodelling } \\
\hline No remodelling & 0 \\
\hline Remodelling with formation & \\
\hline of medullary canal & 2 \\
\hline Formation of a partial cortex & 4 \\
\hline Cortex complete & 6 \\
\hline \multicolumn{2}{|l|}{ Microradiographs } \\
\hline Bone defect & $\mathbf{0}$ \\
\hline Incomplete bone bridging & 2 \\
\hline Complete bone bridging & 4 \\
\hline medullary canal & 6 \\
\hline
\end{tabular}


Undecalcified sections $(30 \mu \mathrm{m}$ and $100 \mu \mathrm{m})$ were placed directly onto a film (Kodak High Resolution S 0343) and exposed to X-rays together with an aluminium step wedge to provide a calibrated density reference scale ( $12 \mathrm{kv} / 15 \mathrm{~mA} / 5 \mathrm{~min}$ for $30 \mu \mathrm{m}$ sections: $20 \mathrm{kv} / 60 \mathrm{~mA} /$ $4 \mathrm{~min}$ for $100 \mu \mathrm{m}$ sections). The numerical equivalents of the grey values of the microradiograph of the step wedge were determined with a photometer at different voltage settings and exposure times, and compared with the radiograph of the tissue specimen. The mineral density was determined from the differing grey values of the radiograph, intermediate values being interpolated. Absolute values were calculated by multiplying the measured value with the absorption coefficient and correcting for the thickness of the specimen at the site of measurement. The results represent the hydroxyapatite content as a percentage of the total volume of bone.

The point of highest mineral density was located on the microradiograph of the $100 \mu \mathrm{m}$ thick section and its mineral content was determined. On the microradiograph of the $30 \mu \mathrm{m}$ section 65000 points were analysed in a field of $10 \mathrm{~mm}^{2}$ using a scanning microscope (LeitzWetzlar) and a computer (Digital Equipment).
In all unhealed specimens, the cut ends of the bone were cone shaped from the growth of new bone. Bone growth was more vigorous from the proximal than the distal fragment. In some animals the shaft distal to the defect showed signs of atrophy.

Histology. The defects were filled with highly vascularised and cell-rich connective tissue. In several specimens, we found remnants of DBM or BMG surrounded by connective tissue. With bank bone implants, no remnants were found in the connective tissue but a few small pieces were incorporated into the newly formed bone at the borders of the defect; these dead fragments were delineated by cement lines and could be clearly identified by the absence of osteocytes. Lymphoplasmocellular infiltrates were not seen in any specimen, but, in three instances, there was leucocyte infiltration of the medullary spaces adjacent to the defect.

The newly formed bone showing cancellous structure revealed extensive osteoblastic seams as well as osteoid, an expression of its continuing transformation.

Microradiography. The ratio of mineralised parts to total bone volume was significantly greater in autogenous cancellous grafts than in the sham group (Table III).
Table II. Healing of the ulnar defect in dogs, evaluated according to the scoring system in Table I.

\begin{tabular}{llr}
\hline Implant group & Number & Points \pm SD \\
\hline Sham & 5 & $3.8 \pm 3.6$ \\
Autogeneic cancellous bone & 5 & $14.4^{*} \pm 3.6$ \\
Bank bone & 5 & $1.4 \pm 0.9$ \\
Demineralised bone matrix & 5 & $7.0 \pm 6.9$ \\
Bone morphogenetic gelatin & 4 & $2.3 \pm 1.5$ \\
\hline *p<0.05 (analysis of variance) &
\end{tabular}

* $p<0.05$ (analysis of variance)
Table III. Morphometric results of microradiographs of specimens after filling the ulnar defect with different materials.

\begin{tabular}{lccccccc}
\hline & $\begin{array}{l}\text { Sham } \\
\text { group }\end{array}$ & $\begin{array}{l}\text { Autogenic } \\
\text { cancellous } \\
\text { bone }\end{array}$ & Bank bone & $\begin{array}{l}\text { Demineralised } \\
\text { bone matrix }\end{array}$ & $\begin{array}{l}\text { Bone } \\
\text { morphogenetic } \\
\text { gelatin }\end{array}$ & $\begin{array}{l}\text { Iliac } \\
\text { crest }\end{array}$ \\
\hline Number & 5 & 5 & 5 & 5 & 4 & 5 \\
$\begin{array}{l}\text { Bone component } \\
\text { (vol \%) } \dagger\end{array}$ & 21.3 & $50.4^{*}$ & 12.1 & 27.9 & 21.5 & 30.1 \\
SD & 10.2 & 12.0 & 7.5 & 10.0 & 4.9 & 9.7 \\
\hline
\end{tabular}

* $p<0.05$ (analysis of variance)

† mineralised parts as a percentage of total volume
Evaluation. We used a scoring system based on the evaluation of the last radiograph and the microradiographs (Table I). For the quantitative evaluation of new bone formation, the hydroxyapatite content and distribution were used. For reference, iliac crest specimens of five dogs were processed like the ulnar specimens. Analysis of variance was used for statistical analysis.

\section{RESULTS}

Radiology. The radiographic scores were much higher for the autogeneic grafts (Table II) and they led to bridging of the defect in all instances. The one gap remaining in an area of newly formed bone was probably a fracture.

None of the other defects healed, except for one of the five treated with demineralised bone matrix.
Implantation of bank bone yielded less bone formation than when the defects were left empty.

\section{DISCUSSION}

Ulnar resection is a useful experimental modei because the bone is easy to expose and because defects longer than $25 \mathrm{~mm}$ do not spontaneously heal (Key 1934). Interposition of the biologically inert Silastic blocks kept space for the implant material and prevented primary regeneration, as proved by the sham group in which no defect healed within 24 weeks. There was no instance of failure of the osteosynthesis.

Unlike Johnson et al (1989), we resected the periosteum over the entire defect, since the periosteum itself can contribute to osteoregeneration. We excised the membrane that had formed around the interposed plastic 
block for the same reason. Autogeneic cancellous bone was the only implant material that led to defect healing. The osteoinductive power of canine bone matrix was not sufficient to contribute significantly to bone regeneration.

We found no difference between the effect of bone morphogenetic gelatin and demineralised matrix, despite the fact that the latter material was sterilised by radiation. In rat experiments, a similar dosage of radiation led to reduction but not to destruction of osteoinductivity (Schwarz et al 1988).

Xenogeneic bovine BMP, the material favoured and used by Urist and his co-workers (Sato and Urist 1985; Nilsson et al 1986; Ferguson et al 1987; Lindholm et al 1988; Johnson et al 1989) is - in contrast to whole demineralised bone matrix - cell-free, which may avoid immune reactions, and is resorbed within a few days (Nilsson et al 1986). Nilsson et al (1986) also showed that dogs responded to bovine BMP, but Johnson et al (1989) found that extensive diaphyseal defects did not heal. Gap healing was only achieved when autogeneic cancellous bone was added to BMP.

We believe that in our model there was minimal regeneration capability, mimicking the clinical conditions of a long-standing diaphyseal defect, and that in such a case no measure can succeed unless autogeneic cancellous bone is transplanted.

No benefits in any form have been received or will be received from a commercial party related directly or indirectly to the subject of this article.

\section{REFERENCES}

Aspenberg P, Lohmander LS, Thorngren K-G. Failure of bone induction by bone matrix in adult monkeys. J Bone Joint Surg [ $\mathrm{Br}$ ] 1988; 70B:625-7.

Ferguson D, Davis WL, Urist MR, Hurt WC, Allen EP. Bovine bone morphogenetic protein (BBMP) fraction-induced repair of craniotomy defects in the Rhesus monkey (Macaca speciosa). Clin Orthop 1987; 219:251-8.

Hosny M, Sharawy M. Osteoinduction in rhesus monkeys using demineralized bone powder allografts. J Oral Maxillofac Surg $1985 ; 43: 837-44$.

Johnson EE, Urist MR, Schmalzried TP, Chotivichit A, Huang HK, Finerman GAM. Autogeneic cancellous bone grafts in extensive segmental ulnar defects in dogs. Clin Orthop 1989; 243: 254-65.
Key JA. The effect of a local calcium depot on osteogenesis and healing of fractures. J Bone Joint Surg 1934; 16:176-84.

Lindholm TC, Lindholm TS, Alitalo I, Urist MR. Bovine bone morphogenetic protein (bBMP) induced repair of skull trephine defects in sheep. Clin Orthop 1988; 227:265-8.

Nilsson OS, Urist MR, Dawson EG, Schmalaried TP, Finerman GAM. Bone repair induced by bone morphogenetic protein in ulnar defects in dogs. J Bone Joint Surg [ Br] 1986; 68-B:635-42.

Sato K, Urist MR. Induced regeneration of calvaria by bone morphogenetic protein (BMP) in dogs. Clin Orthop 1985; 197:301-11.

Schwarz N, Redl H, Schiesser A, et al. Irradiation-sterilization of rat bone matrix gelatin. Acta Orthop Scand 1988; 59:165-7.

Urist M. Bone: formation by autoinduction. Science $1965 ; 150: 893-9$. 